\title{
Bone age, social deprivation, and single parent families
}

\author{
T J Cole, A J L Cole
}

\begin{abstract}
It is well known that deprivation affects bone growth. The study was set up to investigate what aspects of deprivation are of greatest importance. Bone ages of 1593 child trauma patients aged 0-19 years from Middlesbrough General Hospital, Cleveland, were related to local authority ward indices of socioeconomic status (51 wards). After adjustment for chronological age and sex, the mean bone ages in each ward were highly significantly negatively associated with five ward indices of deprivation: the rate of single parent families, low car ownership, unemployment, rented housing, and overcrowding. There was a mean four month deficit in bone age among children living in wards with the highest single parent family rates. The inverse association between deprivation and bone age is unlikely to be causal throughout childhood, as older and younger children were affected to the same extent. However the bone age deficit could be caused by deprivation retarding skeletal maturation during a critical period in early life.
\end{abstract}

\section{(Arch Dis Child 1992;67:1281-5)}

There is considerable evidence that adverse socioeconomic circumstances affect the rate of skeletal maturation, although the mechanisms involved are not clear. Differences in skeletal maturity have been observed among children differing in a variety of ways including geography, income, nutrition, home conditions, and psychosocial factors. ${ }^{1-9}$ However the compared groups have tended to be relatively disparate, in terms either of clinical status or geography, and it is not clear to what extent, within the community, deprivation affects skeletal maturity.

Recent work has shown that poor perinatal growth is a risk factor for ischaemic heart disease, stroke, and obstructive lung disease in later life. ${ }^{10}$ This has been proposed as an example of programming, where circumstances at a critical period in early life dictate the individual's future health status. The present study, covering a small geographic area of Britain, was carried out using radiographs of trauma patients to investigate in more detail the link between skeletal maturity, as measured by Greulich-Pyle bone age, and indices of socioeconomic status. The aim was to find out which indices were most closely associated with skeletal retardation, and to identify at what ages the association was strongest.
Subjects and methods

Some 2000 packets of $x$ ray films, belong to patients who had had hand radiographs for trauma when under the age of 20 years, were retrieved from the archives of Middlesbrough General Hospital, Cleveland. Most patients had been radiographed during the years 1979-81. Over 300 records were discarded, because either all the epiphyses had fused, or the radiographs were missing, technically inadequate or illegible, or the patient did not reside within the boroughs of Middlesbrough or Langbaurgh.

The bone ages were estimated blind by AJLC using the atlas of Greulich and Pyle. ${ }^{11}$ In a minority of cases where the bone age lay between two adjacent standards, the mid-age was used. The subject's identifying number, sex, date of birth and examination, bone age, and local authority ward from their address were then recorded. Race was not recorded, but the subjects were probably almost all white; the population of Cleveland is only about 3\% nonwhite, and of this only a small fraction is AfroCaribbean.

The subjects came from 51 distinct local authority wards. Information on 13 socioeconomic indices for each ward from the 1981 census was obtained, expressed per 1000 households or population as appropriate (see list in table 4).

\section{STATISTICAL METHODS}

The data were scrutinised for anomalies between bone age and chronological age, and patients who had been referred for poor growth rather than trauma were excluded. In addition erroneous dates of birth and examination were corrected.

Multiple regression analysis was used to relate each subject's bone age to chronological age, sex, and the subject's socioeconomic information as obtained from their ward. The chronological age adjustment was done using a polynomial in age. An overall sex effect and interactions of sex with each term of the fitted polynomial were also included. This is equivalent to fitting separate polynomials for the two sexes.

Regression was used to compare the ability of the different ward socioeconomic indices to explain the residual variation in bone age, after adjusting for chronological age and sex. The significance of each ward index was assessed relative to the between ward variation, so that the $t$ statistic for the significance of the index was given by

$$
t=\sqrt{49 \mathrm{R}^{2} /\left(1-\mathrm{R}^{2}\right)},
$$

\author{
Correspondence to: \\ Dr T J Cole. \\ Accepted 26 June 1992 \\ MRC Dunn
Nutrition Centre, \\ Milton Road, \\ Middlesbrough General \\ Hospital \\ Cleveland
}


with 49 residual degrees of freedom, where $R$ was the weighted correlation, across wards, between the mean adjusted bone age and the socioeconomic index, the weightings corresponding to the numbers of subjects in each ward.

\section{Results}

A total of 1683 radiographs from 1593 subjects were available for analysis. Eighty four subjects had more than one radiograph: 80 with two, three with three, and one with five. All such radiographs except the first were excluded from the analysis, leaving a total of 1593 . The age and sex distribution of the sample is given in table 1 . The sex ratio was 63:37, and the modal ages for boys and girls were 14 and 11 years respectively, with a sharp increase in numbers from age 11 .

Table 1 Age and sex distribution of subjects studied

\begin{tabular}{lrrr}
\hline $\begin{array}{l}\text { Age } \\
\text { (years) }\end{array}$ & Boys & Girls & Total \\
\hline $0+$ & & & \\
$1+$ & 9 & 4 & 13 \\
$2+$ & 21 & 13 & 33 \\
$3+$ & 27 & 23 & 44 \\
$4+$ & 23 & 18 & 45 \\
$5+$ & 14 & 23 & 46 \\
$6+$ & 30 & 17 & 31 \\
$7+$ & 33 & 19 & 49 \\
$8+$ & 45 & 21 & 54 \\
$9+$ & 40 & 25 & 78 \\
$10+$ & 50 & 38 & 84 \\
$11+$ & 73 & 34 & 154 \\
$12+$ & 91 & 81 & 158 \\
$13+$ & 105 & 67 & 159 \\
$14+$ & 128 & 54 & 187 \\
$15+$ & 105 & 59 & 149 \\
$16+$ & 84 & 44 & 11 \\
$17+$ & 75 & 27 & 82 \\
$18+$ & 45 & 7 & 1593 \\
Total & 1018 & 1 & \\
\hline
\end{tabular}

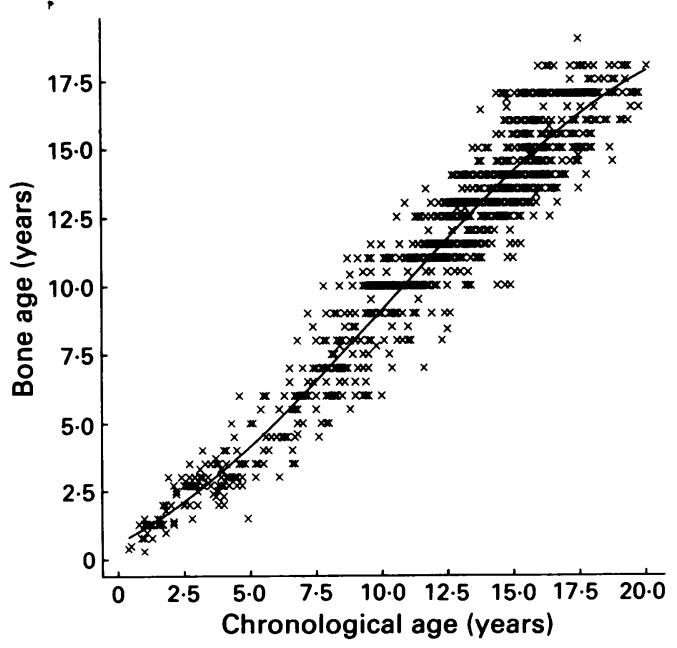

Figure 1 Scatter diagram of Greulich-Pyle bone age versus chronological age in 1018 boys, with the fitted cubic in chronological age.
The subjects came from 51 distinct local authority wards, with a median number of 29 subjects per ward (lower and upper quartiles 20 and 39; range 6-94).

Scatterplots of bone age versus chronological age are shown in figs 1 and 2 for boys and girls, with fitted cubic polynomials in chronological age superimposed. Table 2 gives the regression equations for the polynomials, and also for a simpler linear model containing just age and sex. The linear model shows that, after adjusting for chronological age, mean bone age is 0.27 years greater in the girls than in the boys, and that the age regression coefficient of 0.951 is highly significantly less than $1(t=-7 \cdot 1$, $\mathrm{p}<<0.001$ ).

Table 3 summarises the analysis of variance of bone age after fitting polynomials of increasing degree for the two sexes up to fifth order.

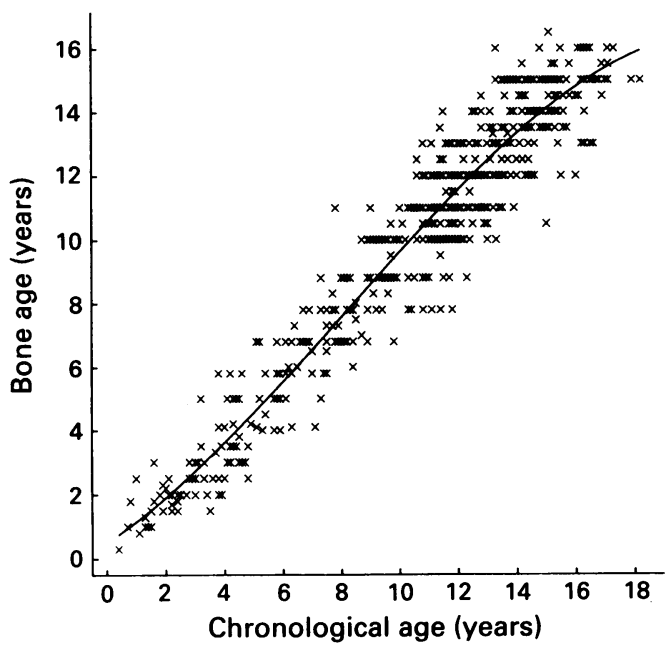

Figure 2 Scatter diagram of Greulich-Pyle bone age versus chronological age in 575 girls, with the fitted cubic in chronological age.

Table 3 The analysis of variance table from the regression of bone age on chronological age polynomials of increasing order. Terms such as Age.Sex indicate the interaction of age and sex, that is the difference between sexes in the age term

\begin{tabular}{|c|c|c|c|c|}
\hline Term & $\begin{array}{l}\text { Degrees of } \\
\text { freedom }\end{array}$ & $\begin{array}{l}\text { Sum of } \\
\text { squares }\end{array}$ & $\begin{array}{l}\text { Mean } \\
\text { square }\end{array}$ & $\begin{array}{l}\text { Variance } \\
\text { ratio }\end{array}$ \\
\hline $\begin{array}{l}\text { Age } \\
\text { Sex } \\
\text { Age.Sex } \text { Age }^{2} \\
\text { Age }^{2} \text {.Sex } \\
\text { Age }^{3} \\
\text { Age. }^{3} \text {.Sex } \\
\text { Age }^{4} \\
\text { Age }^{4} \text {.Sex } \\
\text { Age }^{5} \\
\text { Age'.Sex }^{5} \text {. }\end{array}$ & $\begin{array}{l}1 \\
1 \\
1 \\
1 \\
1 \\
1 \\
1 \\
1 \\
1 \\
1 \\
1\end{array}$ & $\begin{array}{r}27342 \cdot 84 \\
25 \cdot 27 \\
1.70 \\
7 \cdot 17 \\
5.72 \\
56 \cdot 59 \\
0 \cdot 15 \\
1 \cdot 11 \\
0.56 \\
10 \cdot 81 \\
3.15\end{array}$ & $\begin{array}{r}27342 \cdot 84 \\
25.27 \\
1.70 \\
7.17 \\
5.72 \\
56.59 \\
0.15 \\
1.11 \\
0.56 \\
10.81 \\
3.15\end{array}$ & $\begin{array}{c}19897 \cdot 94^{* * *} \\
18 \cdot 39^{* *} \\
1 \cdot 24 \\
5 \cdot 22^{*} \\
4 \cdot 16^{*} \\
41 \cdot 18^{* * *} \\
0 \cdot 11 \\
0 \cdot 81 \\
0 \cdot 41 \\
7 \cdot 86^{* *} \\
2 \cdot 29\end{array}$ \\
\hline Residual & 1581 & $2172 \cdot 54$ & $1 \cdot 37$ & \\
\hline Total & 1592 & $29627 \cdot 61$ & 18.61 & \\
\hline
\end{tabular}

"p<0.05; "** $p<0.01$; **: * $p<0.001$.

Table 2 Regression models of bone age on chronological age and sex. Results are given as regression coefficient (SE) for each term. The linear model is for the two sexes combined

\begin{tabular}{|c|c|c|c|c|c|}
\hline Model & Constant & Female sex & Age & $(A g e-12)^{2}$ & $(\text { Age-12) })^{3}$ \\
\hline $\begin{array}{l}\text { Linear } \\
\text { Cubic for boys } \\
\text { Cubic for girls }\end{array}$ & $\begin{array}{r}-0.307(0.093) \\
-1.164(0.214) \\
0.324(0.272)\end{array}$ & $\begin{array}{l}0.266(0.063) \\
-\end{array}$ & $\begin{array}{l}0.951(0.007) \\
1.029(0.017) \\
0.936(0.022)\end{array}$ & $\begin{array}{l}- \\
-0.0102(0.0023) \\
-0.0243(0.0056)\end{array}$ & $\begin{array}{l}- \\
-0.00189(0.00034) \\
-0.00213(0.00064)\end{array}$ \\
\hline
\end{tabular}


This table shows the significance of each extra term as the order increases, with the linear term being massively significant and accounting for over $92 \%$ of the variation. The cubic terms and quintic terms are also highly significant $(\mathrm{p}<0.01)$, but they account for only a small proportion of the total variation. There is also a highly significant difference in mean bone age between the sexes, but the only significant agesex interaction is the quadratic term $(p<0.05)$.

After adjusting for sex and age using the sex specific cubic polynomials, the mean adjusted bone ages for each ward were significantly different from each other $(F=1.48$ on 50 and $1535 \mathrm{df}, \mathrm{p}=0.02$ ), with a range in mean bone age of 1.23 years. Table 4 summarises the ability of each of the 13 socioeconomic indices to explain the ward differences in bone age. Five of the 13 indices are highly significant, and the rate of single parent households in each ward is the best predictor $(r=-0.49$, regression coefficient $-0.00086, p=0.0003)$. Car ownership, unemployment, rented housing, and overcrowding are also highly significant, but become insignificant after adjusting for the single parent household rate. Three of the other insignificant indices relate to the numbers of old people in each ward.

Figure 3 shows the plot of mean adjusted

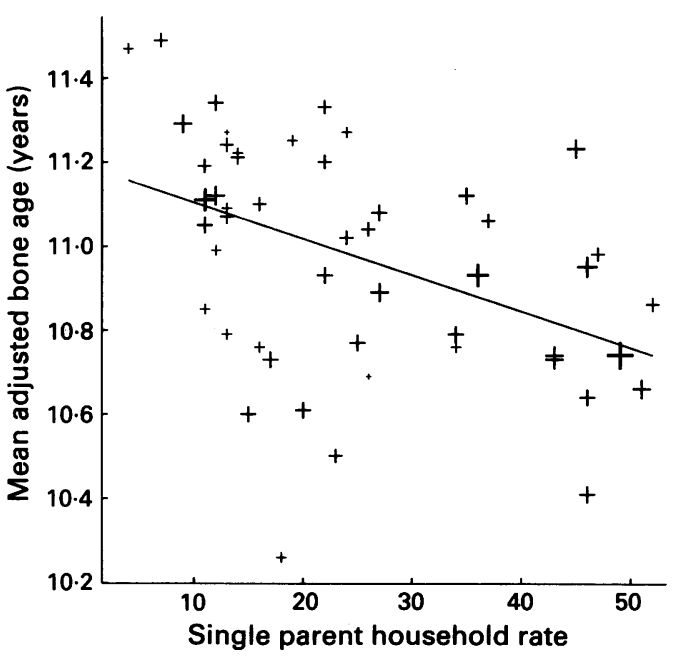

Figure 3 Scatter diagram of mean adjusted bone age versus the rate of single parent households in 51 local authority wards, with the fitted regression line. The size of each point is proportional to the number of subjects in that ward.

Table 4 The relative importance of 13 socioeconomic indices for explaining the difference in bone age between wards, after adjustment for chromological age and sex. Data are the correlations and regression coefficients of mean adjusted bone age on each index in turn, weighted according to the numbers of subjects in each ward. Each regression coefficient shows the effect on a ward's mean adjusted bone age, in years, of a unit change in the index

\begin{tabular}{llll}
\hline Socioeconomic index (per 1000) & Correlation & $\begin{array}{l}\text { Regression } \\
\text { coefficient }\end{array}$ & $\begin{array}{l}\text { Significance } \\
\text { level }\end{array}$ \\
\hline Households with one parent & -0.49 & -0.00858 & 0.0003 \\
Households with no car & -0.46 & -0.00055 & 0.0008 \\
Unemployed males 16-64 years & -0.45 & -0.00119 & 0.0008 \\
Households in rented housing & -0.43 & -0.00036 & 0.002 \\
Households with more than one person/room & -0.42 & -0.00324 & 0.002 \\
Households with three or more dependent children & -0.34 & -0.00314 & 0.02 \\
Children under 5 years & -0.25 & -0.00366 & 0.08 \\
Households of a pensioner alone & -0.24 & -0.00167 & 0.09 \\
Households with pensioners only & -0.11 & -0.00054 & 0.5 \\
Adults over 74 years & -0.09 & -0.00156 & 0.6 \\
Head of household born in New Commonwealth & -0.08 & -0.00045 & 0.6 \\
Households sharing/lacking a bath & -0.07 & -0.00069 & 0.7 \\
Households in multioccupied dwellings & 0.03 & 0.00062 & 0.9 \\
\hline
\end{tabular}

bone age for each ward plotted against the corresponding single parent household rate, with the fitted regression line superimposed. The size of each point reflects the number of subjects in the ward. The difference in mean adjusted bone age between wards with low (10 per 1000) and high (50 per 1000) single parent household rates is 0.34 years, or four months.

Importantly, there is no evidence that the effect of the single parent index on bone age varies by age or sex ( $t$ values for interaction terms of single parent index with age and sex 0.66 and 0.92 respectively, $p>0.3$ ). Thus the effect is the same at all ages.

\section{Discussion}

The study has demonstrated a highly significant negative association between the skeletal maturity of children radiographed for trauma and indices of socioeconomic status in the wards where they live. The best single predictor is the ward rate of single parent households, but other highly significant indices are low car ownership, unemployment, rented housing, and overcrowding.

Two factors relating to the study's validity need to be considered: (i) how valid GreulichPyle bone age is for measuring skeletal maturation and (ii) how representative trauma patients age of the population of Cleveland children. The method of Tanner and Whitehouse (TW2) ${ }^{12}$ has been advocated for the estimation of bone age ${ }^{13}$ rather than Greulich-Pyle, because it is claimed to be more accurate. The greater time and effort required by the TW 2 method is cited as being more than offset by its greater accuracy and precision. However the authors have found previously that Greulich-Pyle, although providing an underestimate of chronological age, is at least as consistent as TW2, with lower interobserver variation. ${ }^{14}$ Other workers have reached similar conclusions, and have advocated the Greulich and Pyle method for population based studies of skeletal age. 11516 In this study the inherent under estimation of the method is adjusted for by regression analysis, and the absolute bone age is of less importance than the discrepancy between chronological and bone age.

The slope of the regression line relating bone age to chronological age in the present study is 0.951 with a SE of 0.007 (table 3 ), very similar to the study of Cole et al where the regression coefficient was 0.939 (SE 0.031$).{ }^{14}$ There is also no evidence that the age coefficient differs between the sexes (table 3 ), and the sex specific cubic curves are very similar in shape (figs 1 and 2 ). More curious is the highly significant difference in mean adjusted bone age between the sexes (table 2), with the girls 0.27 years older than the boys. This implies that compared with children in the original Brush Foundation sample, ${ }^{11}$ Cleveland girls are relatively more advanced than Cleveland boys. Why this should be is not obvious, although two other surveys have seen the same sex effect. ${ }^{1}$ It may mean that boys are more fragile than girls in the face of deprivation, but alternatively and perhaps more convincingly, the Brush Foundation's strict 
selection criteria may have introduced a sex bias in the reference data.

The present study sample, children brought to hospital for trauma, is clearly not a random sample of Cleveland children. For a start its age distribution is weighted towards the teenage years, and boys are over represented (table 1). It is also likely to be weighted towards children living nearer to Middlesbrough General Hospital. Nevertheless these and other possible biases can only affect the validity of the observed association to the extent that they might actually generate it. For this to happen, children from the more deprived wards would need to be more likely to attend hospital for trauma if they were skeletally immature, whereas in the well off wards the bias would need to operate the other way. This, though possible, is unlikely. One other possibility, that the reading of the radiographs was biased, can be ruled out as they were read blind.

Thus the association between skeletal maturity and socioeconomic status is likely to be valid. An association in this detail has not previously been demonstrated, and the obvious question is: Is it causal? The possible alternatives are that reduced maturation leads to deprivation (which is not feasible), or that deprivation causes reduced maturation, or that both deprivation and reduced maturation are caused by some other common factor.

Rona and Chinn showed an association of height in childhood with deprivation, which they argued arises from a period in early life when deprivation causes growth faltering. ${ }^{17}$ They found that after adjusting for father's social class, parental height, family size and child's birth weight, primary schoolchildren of unemployed fathers were shorter than children whose fathers were employed. However when they looked at height gain over two years there was no longer an association with unemployment. This could be explained by unemployment having a causal effect on height growth earlier in life, ${ }^{18}$ but not later, so that the deficit seen at school age dates back to the preschool period.

In the present study the linear relationship between bone age and chronological age is shifted downwards in the presence of deprivation, that is the constant term (intercept) is reduced. However there is no evidence that the slope of the line is affected by deprivation, so that children from all wards, whatever their socioeconomic status, track along lines of the same slope. This pattern can be explained by arguing that, just as for height growth, deprivation has a causal negative influence on bone age early in life, but that thereafter it has no effect. Thus young children from the more deprived wards become skeletally retarded compared with well off children, but once they are past the vulnerable period they mature at the same rate as everybody else, so that their bone age deficit remains the same throughout the growth period.

This explanation presupposes that each ward has a level of deprivation associated with it which determines the amount of retardation that infants living there are likely to experience. The causal relationship, if it exists, is thus between the deprivation of the ward and the retardation of infants living there. In practice one cannot measure the actual level of deprivation that each child experienced as an infant, partly because the avaliable indices were for 1981 , a time when most of the sample were no longer infants. But in addition a substantial proportion of them would have moved house since infancy, so that their current address would be of even less relevance.

For these reasons each child's current address has to be viewed as a proxy for their address, and hence their degree of deprivation, in infancy. It is reasonable to assume that on average, relative deprivation does not change as children grow up, whether or not they move house. Children living in the same area ought to have experienced the same level of deprivation in infancy whether or not they are born locally. Thus the argument for causality is an indirect one, that current ward deprivation acts as a proxy for deprivation in infancy, and it is this which causally affects skeletal maturation.

The alternative explanation for the observed association is that both bone age deficit and deprivation are mediated by a third, probably genetic factor. However Rona and Chinn showed that genes fail to explain the height-unemployment link, as it survives adjustment for parental height and child birth weight. ${ }^{17}$ Part of the height deficit in the children of unemployed parents is likely to be due to skeletal retardation, so that this also appears to survive adjustment for genetic factors. Thus a genetic explanation for the link is unlikely.

If deprivation is the causal agent, then the indices of deprivation found to be significant here, that is single parent, low car ownership, unemployment, rented housing and overcrowding, must be proxies for factors affecting the growth of young children. The indices all represent poverty in some sense, but it is striking that the most significant of them, the rate of single parent families, is the only one that relates directly to child care. Thus the study provides evidence to support the hypothesis that deprivation in early life leads to skeletal retardation, and furthermore it highlights single parent families as being particularly at risk. This fits in with the concept of a critical period in infancy when adverse conditions have long term consequences on health, suggesting that deprivation at this time is of fundamental importance. $^{10}$ The authors would like to acknowledge the advice and en-
couragement of Dr Erasmus Harland and Dr Geoffrey Wyatt. They also thank Mr S Turner and Mr A Tinkler of the Cleveland County Council Research and Intelligence Unit for their help in obtaining the census data.
obuty Council Research

1 Andersen E. Skeletal maturation of Danish school children in relation to height, sexual development, and social conditions. Acta Paediatr Scand 1968; suppl 185:1.

2 Low WD. Relation between socio-economic status and skeletal maturation of Chinese children. $Z$ Morphol Anthropol 1972;64:1-11.

3 Garn SM, Sandusky ST, Rosen NN, Trowbridge F. Economic impact on postnatal ossification. Am f Phys Anthropol 1973;38:1-3.

4 Shakir A, Zaini S. Skeletal maturation of the hand and wrist of young children in Baghdad. Ann Hum Biol 1974;1: 189-99.

5 Roche AF, Roberts J, Hamill PVV. Skeletal maturity of 
children 6-11 years: racial, geographic area, and socioeconomic differentials, United States. Vital Health Stat [11] 1975;149:1-81.

6 Puri RK, Khanna KK. Skeletal changes in protein calorie malnutrition. Indian Pediatr 1976;13:833-6.

7 Roche AF, Roberts J, Hamill PVV. Skeletal maturity of children 12-17 years: racial, geographic area, and socioeconomic differentials, United States, 1966-1970. Vital Health Stat [11] 1978;167:1-98.

8 Kristmundsdottir F, Burwell RG, Marshall WA, Small P. Cross-sectional study of skeletal maturation in normal children from Nottingham and London. Ann Hum Biol 1984;11:133-9.

9 Alcazar ML, Alvear J, Muzzo S. Influencia de la nutricion en el desarrollo oseo del niño (Influence of nutrition on the bone developm

10 Barker DJP. The intrauterine origins of cardiovascular and obstructive lung disease in adult life. The Marc Daniels obstructive lung disease in adult life. The Marc Daniels
Lecture 1990. f R Coll Physicians Lond 1991;25:129-33.
11 Greulich WW, Pyle SI. Radiographic atlas of skeletal development of the hand and wrist. 2nd Ed. Stanford: Standford University Press, 1959.

12 Tanner JM Whitehouse RH, Healy MIR, Goldstein $H$ Standards for skeletal age. Paris: Centre de L'Enfance, 1975.

13 Buckler, JMH. Comparison of systems of estimating skeletal age. Arch Dis Child 1977;52:667-70.

14 Cole AJL, Webb L, Cole TJ. Bone age estimation: a comparison of methods. Br I Radiol 1988;61:683-6.

15 Roche AF, Eyman SL, Davila GH. Skeletal age prediction. J Pediat 1971;78:997-1003.

16 Blanksby BA, Brogan WF, McKnight HP, Sprague PL A skeletal age survey of primary school children in Western Australia. Australian Paediatric foumal 1975;11:169-71.

17 Rona RJ, Chinn S. Father's unemployment and height of primary school children in Britain. Ann Hum Biol 1991;18: 441-8.

18 Cole TJ, Donnet ML, Stanfield JP. Unemployment, birthweight, and growth in the first year. Arch Dis Child 1983; 58:717-21.

\section{Ciprofloxacin toxicity}

Ciprofloxacin is a fluoroquinolone antibiotic which is active against Gram positive and Gram negative bacteria, including Pseudomonas aeruginosa, and aminoglycoside and cephalosporin resistant enterobacteriaciae, chlamydiae, and rickettsiae. Because it has been shown to be toxic to joint cartilage in some growing animals its use in children has been frowned upon. The British National Formulary (September 1991) says that it is not recommended in children or growing adolescents but gives dosage recommendations for children for use 'where benefit outweighs risk'. It has been used in children to treat pseudomonal infection in cystic fibrosis and most of the adverse effects so far reported seem to have been in this context. A 16 year old girl developed swollen knees ${ }^{1}$ and a 14 year old, benign intracranial hypertension. ${ }^{2}$ Interstitial nephritis was reported in a small series of cystic fibrosis patients in Seattle, Washington. ${ }^{3}$ An 11 year old boy, who did not have cystic fibrosis, was treated for typhoid fever and developed interstitial nephritis with acute renal failure. ${ }^{4}$

Because of its antibacterial spectrum, and in particular its activity against pseudomonas and against coliform organisms resistant to other antibiotics, the use of ciprofloxacin in the newborn may be attractive. A report from Thailand (Pagarkrong Lumbiganon and colleagues, Pediatric Infectious Disease Fournal 1991;10: 619-20) records its use during an outbreak of severe neonatal klebsiella infection. Thirteen babies were treated; three died during the acute illness and two died later from other causes. Five of the remaining eight children were seen at between 12 and 23 months of age and two had greenish discoloration of the teeth. They had both been given many other drugs but none known to discolour the teeth.

The association is suggestive but does not prove that ciprofloxacin was responsible. It was tooth discoloration, of course, which put paid to the use of tetracyclines in children. The drug might still have a place in paediatric therapeutics when resistance to other antibiotics is a problem but clearly its use should be carefully monitored until we have a better idea of its risks.

1 Alfaham M, Holt ME, Goodchild MC. Arthropathy in a patient with cystic fibrosis taking ciprofloxacin. BMf 1987;295:699.

2 Winrow AP, Supramaniam G Benign intracranial hypertension after ciprofloxacin

3 Stutman HR. Summary of a workshop on ciprofloxacin use in pediatric patients with cystic fibrosis. Pediatr Infect Dis $\mathcal{7}$ 1987;6:932-5.

cystic fibrosis. Pediatr Infect Dis f 1987;6:932-5.
4 Simpson J, Watson AR, Mellersh A, Nelson CS, Dodd K. Typhoid fever, ciprofloxacin, and renal failure. Arch Dis Child 1991;66:1083-4. 